\title{
Determination of the Hypertrophic Site of the Left Ventricle by Body Surface Mapping in Patients with Hypertension
}

\author{
Hikaru Hoshi, M.D., Isao Kubota, M.D., Kozue Ikeda, M.D., \\ Kai Tsuikr, M.D., and Shoji Yasur, M.D.
}

SUMMARY

To estimate the hypertrophic sites of the left ventricle by body surface mapping (MAP), we performed MAP in 55 patients with hypertension and compared the MAP data with echocardiographic findings. MAP data were analyzed using the departure map technique reported by Flowers et al. The mean and standard deviation (SD) of the normal control were obtained from 40 normal volunteers. We constructed departure maps at 20,30,40,50 and $60 \mathrm{msec}$ from the onset of the QRS. Each map indicates the area of abnormally increased potential outside the normal range at the time.

Subjects were classified into 5 groups according to the appearance time of the abnormal positive area. Septal thickness was significantly increased in groups that had an abnormal positive area at $20 \mathrm{msec}$, and left ventricular posterior wall thickness was significantly increased in the groups that had an abnormal positive area at $60 \mathrm{msec}$. We postulate that the increased electrical potential due to hypertrophy of the interventricular septum is represented by the abnormal positive area at 20 $\mathrm{msec}$, and the increased potential of the left ventricular posterior wall by the abnormal positive area at $60 \mathrm{msec}$.

MAP, especially the departure map technique, is a useful method to detect the abnormal electrical potential distribution in patients with left ventricular hypertrophy.

\section{Additional Indexing Words:}

Body surface mapping Departure map Left ventricular hypertrophy Hypertension

THE conventional electrocardiogram (12-lead EGG and vectorcardio1 gram) is widely used for the diagnosis of left ventricular hypertrophy $(\mathrm{LVH})$, but it is difficult to determine the site of hypertrophy. In body surface mapping, electrocardiographic lead points spread over the entire

From the First Department of Internal Medicine, Yamagata University School of Medicine, Yamagata.

Address for reprint: Hikaru Hoshi, M.D., First Department of Internal Medicine, Yamagata University School of Medicine, Zao-Iida, Yamagata 990-23, Japan.

Received for publication October 16, 1986.

Manuscript revised February 7, 1987. 
thorax. Thus, it offers information about the potential distribution of the back and the upper and lower anterior chest which are hard to derive using the 12-lead electrocardiogram and vectorcardiogram. Using the departure map technique, ${ }^{1-3)}$ we can detect abnormal potential distribution outside the normal range, and can analyze electrical events in more detail.

We performed body surface mapping in patients with hypertension, and analyzed it using the departure map technique. The result was compared with the values determined by M-mode echocardiogram.

\section{Subjects AND METHODS}

Subjects:

Subjects in this study were 55 patients with hypertension who underwent body surface mapping and echocardiography at Yamagata University Hospital from April 1, 1982 to September 30, 1984. They were 33-70 years old (mean 50); 31 men and 24 women. Known duration of hypertension was 0.5 years to 28 years (mean 7.5 ).

Hypertension was defined as systolic pressure consistently greater than $160 \mathrm{mmHg}$ and/or diastolic pressure consistently greater than $95 \mathrm{mmHg}$ at least 4 weeks before the study. Cases with electrocardiographic findings of myocardial infarction, bundle branch block or hemiblock or WPW syndrome were excluded.

Forty normal volunteers were also studied (the normal group). They were all men, 22 to 52 years of age (mean 33). All had normal physical and electrocardiographic findings. None of them had a history of heart disease or hypertension.

\section{Body surface mapping:}

Body surface mapping was performed using a body surface potential mapping system, HPM-5100S unit (Chunichi Denshi Co.), within 2 weeks of the M-mode echocardiogram. Since the procedure for data sampling and processing has been described in detail elsewhere, ${ }^{4}$ ) it will be reviewed here only briefly. Eighty-seven unipolar ECGs distributed over the entire thoracic surface with Wilson's central terminal as reference, standard 12-lead EGGs and the Frank X, Y, Z ECGs are sampled simultancously (Fig. 1). Then, the stored signals of each ECG are displayed on a graphic terminal (TEKTRONIX 4006-1). If noise is detected in any of the signals, data sampling is repeated. The flat portion of the PQ segment is chosen for the baseline. After the baseline adjustment, the data are recorded in a magnetic cassette tape in a digital format. This system has a resolution of $10 \mu \mathrm{V}$, in 


\section{Lead points}

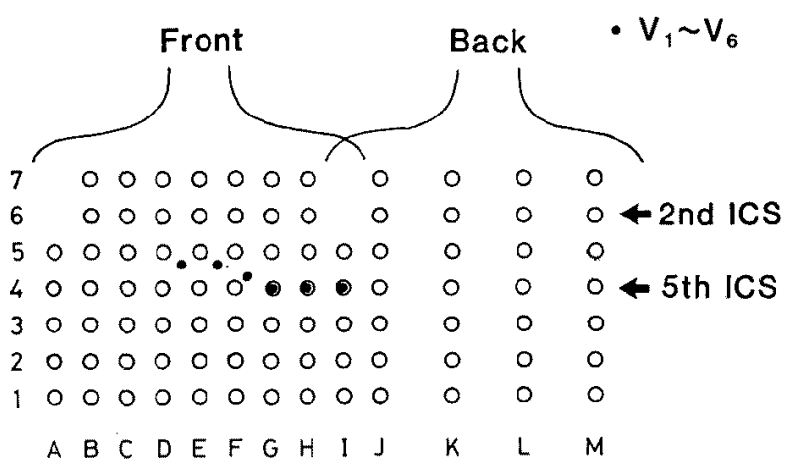

Fig. 1. Electrode sites on the body surface in mapping. Eighty-seven lead points are arranged latticelike ( $13 \times 7$ matrix) except for 4 lead points in both midaxillary regions. Columns $\mathrm{A}, \mathrm{E}$ and $\mathrm{I}$ are positioned in the right midaxillary, midsternal and left midaxillary lines, respectively. Columns B-D and F-H are evenly spaced between columns A-E and E-I, respectively. Column $\mathrm{J}$ is located so as to make the distance between columns $\mathrm{I}$ and $\mathrm{J}$ equal to that between columns $\mathrm{H}$ and $\mathbf{I}$. Column $\mathrm{M}$ is located so as to make the distance between columns $\mathrm{M}$ and $\mathrm{A}$ equal to that between columns $\mathrm{A}$ and $B$. Columns $K$ and $L$ are evenly spaced between columns $J$ and $M$. Lead points $\mathrm{E} 6$ and $\mathrm{E} 4$ are located on the 2nd and 5th intercostal spaces, respectively. Row 5 is located in the center of rows 6 and 4. Rows 7 and 3-1 are located so as to make the distances between adjacent rows equal. The location of the standard $V_{1}$ to $V_{B}$ leads is indicated by dots. ICS $=$ intercostal space.

the dynamic range $\pm 5 \mathrm{mV}$, with a sampling rate of 1,000 samples/sec/channel. The data sampling is done at the resting expiratory level in the supine position.

The ECG signals were processed off line on a minicomputer (Texas Instrument 980-B). For this study, the onset and the offset of the QRS were determined manually from superimposed Frank X, Y, Z leads and the spatial magnitude. The mean and standard deviation (SD) of the normal control were obtained from the normal group. The following analysis was done for each subject in the hypertension group and the normal group.

Departure maps of the isopotential maps at 20,30,40,50 and $60 \mathrm{msec}$ from the onset of the QRS were made according to the method reported by Flowers et al." $\quad$ For this study, departure index (DI) was calculated by the following formula for each lead, and the distribution of DI was displayed as the departure map.

$$
\text { DI }=\frac{\text { potential }- \text { mean of the normal control potential }}{\text { SD of the normal control potential }}
$$


When DI was more positive than +2 , we judged it to be abnormal. On the departure map, the area where the DI was more positive than +2 was designated the $+2 \mathrm{SD}$ area.

On each map, the rectangular area represents the torso surface, with the left half reflecting the anterior chest and the right half the back. Thus, both the right and left edges represent the right midaxillary line. Each contour line connects points of equal DI, and the sites of the maximum and the minimum are indicated by + and - . The dotted area represents the $+2 \mathrm{SD}$ area.

In each patient, the precordial voltage combination of Sokolow and Lyon was measured as $S V_{1}$ the larger $R$ wave in $V_{5}$ or $V_{6}$ of the 12-lead ECG. ${ }^{51,6)}$

\section{M-mode echocardiogram:}

M-mode echocardiograms were recorded using standard techniques with $2.0 \mathrm{MHz}$ transducers interfaced to a Hitachi EUB-10. Patients were examined in supine or left decubitus position. The transducer was placed in the third to fifth intercostal space. M-mode echocardiographic findings were analyzed independently and without knowledge of clinical data by 2 investigators. Interventricular septal thickness (ST), posterior wall thickness (PWT) and left ventricular end-diastolic internal diameter (LVID) were measured according to the recommendations of the American Society of Echocardiography. ") Left ventricular mass (LVM) was calculated by the following equation. ${ }^{8)}$

$$
\mathrm{LVM}=1.04\left[(\mathrm{LVID}+\mathrm{PWT}+\mathrm{ST})^{3}-\mathrm{LVID}^{3}\right]-13.6(\mathrm{~g})
$$

The unpaired Student's t-test was used for statistical comparisons. Statistical significance was considered to be $p<0.05$. Values presented in tables and figures are expressed as mean $\pm S D$.

\section{RESULTS}

Fig. 2A shows the isopotential maps of a 37-year-old normal man. Maximal potential was located on the middle anterior chest at $20 \mathrm{msec}$, and moved leftward and slightly downward thereafter. At $50 \mathrm{msec}$, the maximum was located on the left lateral chest and eventually reached the back at $60 \mathrm{msec}$. In this case a $+2 \mathrm{SD}$ area was not observed in any of the departure maps (Fig. 2B).

Fig. 3 shows the departure maps of a 53-year-old man with hypertension (ST $13 \mathrm{~mm}$, PWT $13 \mathrm{~mm}$, LVM $340 \mathrm{~g}$ ). A +2SD area was found on 

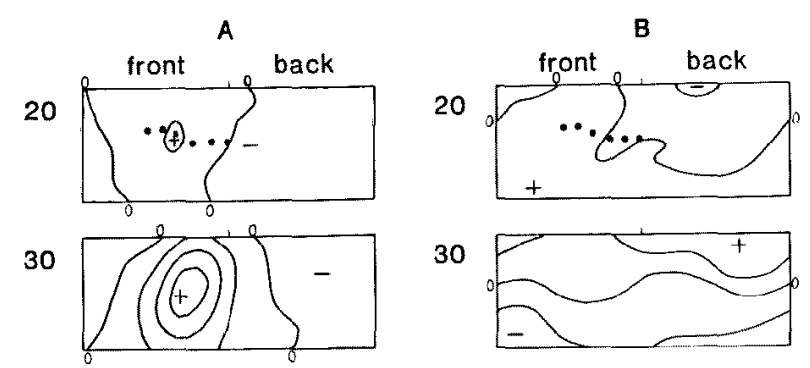

40

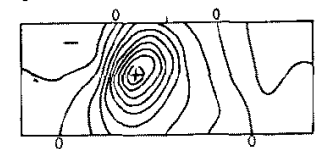

50
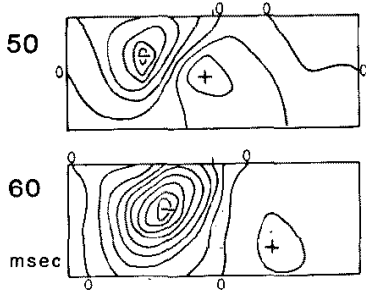

30

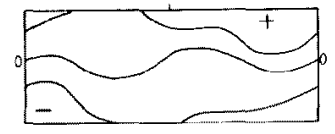

40

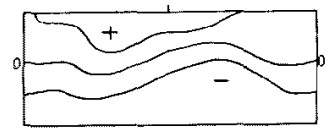

50
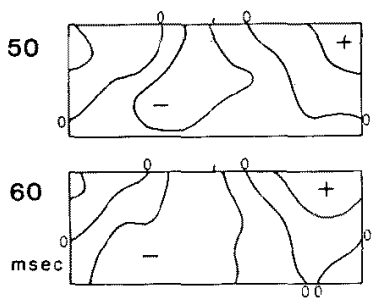

Fig. 2. Body surface isopotential maps (A) and departure maps (B) of a normal 37-year-old man. These maps are presented at $10 \mathrm{msec}$ intervals from 20 to $60 \mathrm{msec}$ after the onset of the QRS. In isopotential maps (A), isopotential lines are drawn at intervals of $0.2 \mathrm{mV}$. + and - indicate a maximum and a minimum, respectively. In departure maps (B), each contour line connects points of equal DI. No $+2 \mathrm{SD}$ area was found on any departure maps in this case.

the left middle anterior chest at $20 \mathrm{msec}$, and shifted leftward and slightly downward thereafter and was located mainly on the back at $60 \mathrm{msec}$. The location of the +2SD area was quite similar to the location of maximal potential observed on the isopotential maps in Fig. 2A.

Not all patients had a +2SD area throughout from $20 \mathrm{msec}$ to $60 \mathrm{msec}$; that is, each patient was different in terms of the appearance time of the $+2 \mathrm{SD}$ area. But, when $\mathrm{a}+2 \mathrm{SD}$ area appeared, the location was similar to that of the representative case at that time, on the anterior chest at 20 $\mathrm{msec}$, the left anterior to lateral chest at 30 and $40 \mathrm{msec}$, the left lateral chest at $50 \mathrm{msec}$, and the left lateral chest to the back at $60 \mathrm{msec}$. Patients were classified into 5 groups according to the appearance time of the +2SD area (Fig. 4).

Group 1; No +2SD area on any of the departure maps.

Group $2 ;+2 \mathrm{SD}$ area present at $20 \mathrm{msec}$ and not at $60 \mathrm{msec}$.

Group $3 ;+2 \mathrm{SD}$ area present at 30,40 or $50 \mathrm{msec}$, and not at 20 or $60 \mathrm{msec}$. 


\section{T.S. $53 y$}

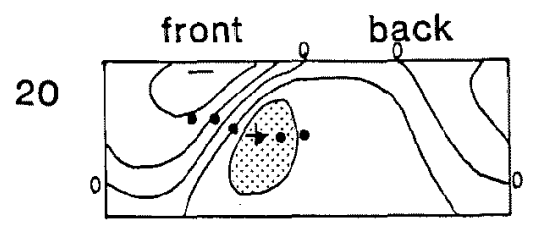

30

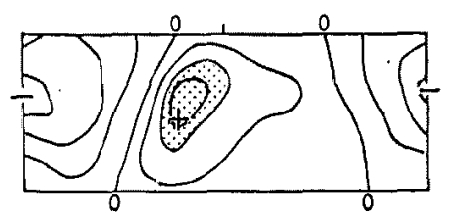

40

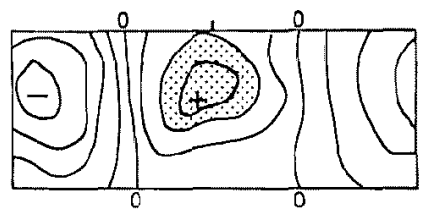

50
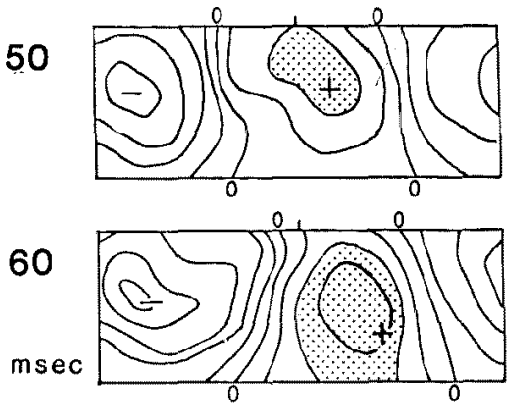

Fig. 3. Departure maps of a 53-year-old man with hypertension. The dotted areas represent the $+2 \mathrm{SD}$ area. The $+2 \mathrm{SD}$ area was located on the left middle anterior chest at $20 \mathrm{msec}$, and shifted leftward and slightly downward thereafter and was located mainly on the back at $60 \mathrm{msec}$.

Group 4; +2SD area present at $60 \mathrm{msec}$ and not at $20 \mathrm{msec}$.

Group 5; +2SD area present at 20 and $60 \mathrm{msec}$.

Table I summarizes age, sex, known duration of hypertension and 12lead ECG findings $\left(\mathrm{SV}_{1}+\mathrm{RV}_{5}\right.$ or $\left.\mathrm{V}_{6}\right)$ of the 5 groups. The patients in group 1 were mostly young and they were significantly younger than those in the other groups. The ages of the patients in groups 2-5 were not different from each other. Known duration of hypertension was significantly shorter in groups 1,2 and 3 than in groups 4 and $5 . \quad S V_{1}+R_{5}$ or $V_{6}$ had the tendency to increase with the number of the group, from 1 to 5 . In group $5, \mathrm{SV}_{1}+\mathrm{RV}_{5}$ or $\mathrm{V}_{6}$ was $5.1 \pm 1.0 \mathrm{mV}$, and this was significantly greater than those in groups $1,2,3$ and $4(p<0.05)$.

Echocardiographic findings (ST, PWT, LVM) of the 5 groups are 


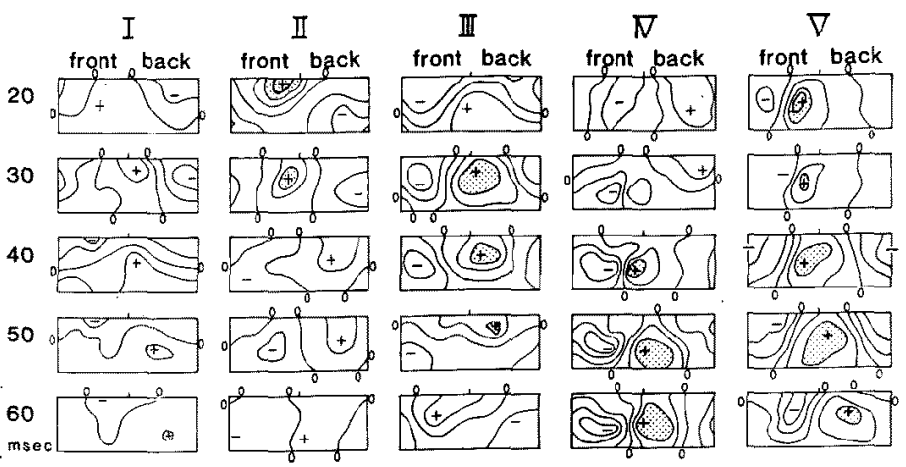

Fig. 4. Departure maps of representative cases of each group (groups 1-5). In the group 1 case, no $+2 \mathrm{SD}$ area was found on any departure map, and in the group 2 case, a $+2 \mathrm{SD}$ area was found at $20 \mathrm{msec}$ and not found at $60 \mathrm{msec}$. The group 3 case had $\mathrm{a}+2 \mathrm{SD}$ area at 30,40 and $50 \mathrm{msec}$, and not at 20 or $60 \mathrm{msec}$. In the group 4 case, a $+2 \mathrm{SD}$ area was found at 60 msec, but not found at $20 \mathrm{msec}$. In the group 5 case, a $+2 \mathrm{SD}$ area was found at $20 \mathrm{msec}$ and $60 \mathrm{msec}$.

Table I. Ages, Known Duration of Hypertension and 12-lead ECG Findings $\left(\mathrm{SV}_{1}+\mathrm{RV}_{5}\right.$ or $\left.\mathrm{V}_{6}\right)$ by Group

\begin{tabular}{c|c|c|c|c|c}
\hline Group & $\mathrm{N}$ & (F) & $\begin{array}{c}\text { Age } \\
(\mathrm{yrs})\end{array}$ & $\begin{array}{c}\text { Known duration } \\
\text { of HT (yrs) }\end{array}$ & $\begin{array}{c}\mathrm{SV}_{1}+\mathrm{RV}_{5} \text { or } \mathrm{V}_{6} \\
(\mathrm{mV})\end{array}$ \\
\hline 1 & 6 & 5 & $38.4 \pm 8.4 *$ & $4.3 \pm 6.1$ & $3.2 \pm 0.7$ \\
2 & 14 & 7 & $50.9 \pm 10.3$ & $3.9 \pm 3.5$ & $3.6 \pm 0.8$ \\
3 & 17 & 7 & $50.8 \pm 10.1$ & $4.0 \pm 3.4$ & $3.7 \pm 1.4$ \\
4 & 9 & 2 & $51.0 \pm 9.9$ & $12.9 \pm 5.4 * *$ & $4.0 \pm 0.9$ \\
5 & 9 & 3 & $46.8 \pm 11.3$ & $13.0 \pm 4.3 * *$ & $5.1 \pm 1.0 *$ \\
\hline Total & 55 & 24 & $50.0 \pm 10.7$ & $7.5 \pm 7.4$ & $3.8 \pm 1.3$
\end{tabular}

mean $\pm \mathrm{SD} . \quad * \mathrm{p}<0.05, * * \mathrm{p}<0.01$.

Table II. Echocardiographic Findings by Group

\begin{tabular}{c|c|c|c}
\hline Group & ST (mm) & PWT (mm) & LVM (g) \\
\hline 1 & $10.2 \pm 1.8$ & $9.6 \pm 1.4$ & $191 \pm 38$ \\
2 & $12.9 \pm 1.6^{*}$ & $9.9 \pm 1.0$ & $206 \pm 33$ \\
3 & $11.4 \pm 1.4$ & $11.0 \pm 1.9$ & $235 \pm 62$ \\
4 & $11.6 \pm 0.8$ & $12.7 \pm 1.9 *$ & $303 \pm 48^{* *}$ \\
5 & $13.9 \pm 2.2^{* *}$ & $13.6 \pm 2.0^{* *}$ & $323 \pm 66^{* *}$ \\
\hline Total & $12.0 \pm 1.8$ & $11.3 \pm 2.2$ & $250 \pm 70$
\end{tabular}

$\operatorname{mean} \pm \mathrm{SD} . * \mathrm{p}<0.05, * * \mathrm{p}<0.01$.

$\mathrm{ST}=$ interventricular septal thickness; $\mathrm{PWT}=$ left ventricular posterior wall thickness; LVM = left ventricular mass. 

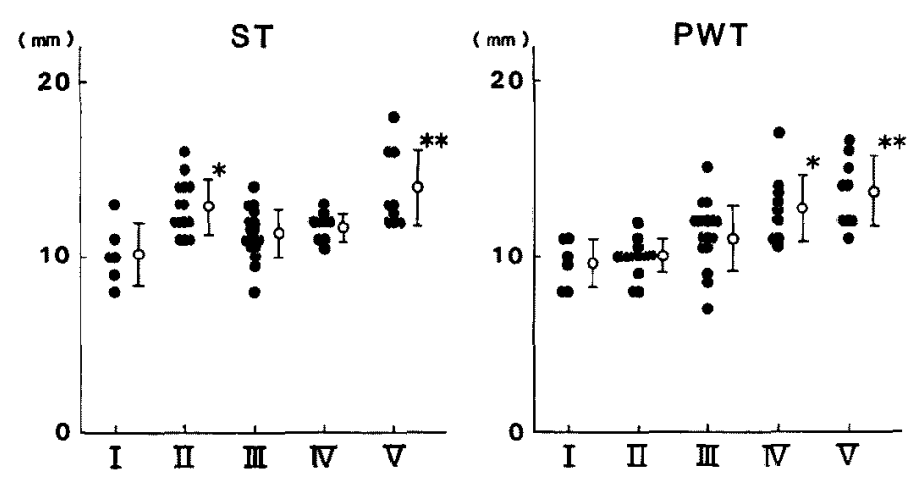

Fig. 5. Interventricular septal thickness (ST) and left ventricular posterior wall thickness (PWT) in each group. In groups 2 and 5, ST was significantly greater than in groups 1,3 and 4 . In groups 4 and 5, PWT was significantly greater than in groups 1,2 and $3 . * p<0.05, * * p<0.01$.

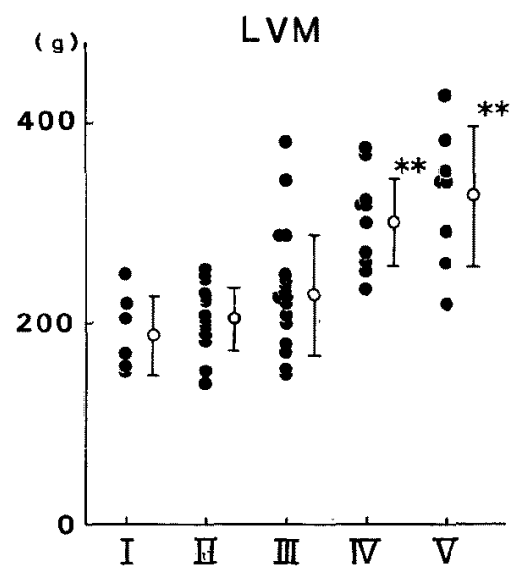

Fig. 6. Left ventricular mass (LVM) in each group. LVM had the tendency to increase with the number of the group from 1 to 5 , and was significantly increased in groups 4 and 5 in comparison with groups 1,2 and 3 . ** $\mathrm{p}<0.01$.

shown in Table II. In groups 2 and 5, ST was significantly greater than in groups 1,3 and 4 ( $\mathrm{p}<0.01$; Fig. 5). In groups 4 and 5, PWT was significantly greater than in groups 1,2 and $3(\mathrm{p}<0.01$; Fig. 5). LVM had a tendency to increase with the number of the group from 1 to 5 , and was significantly greater in groups 4 and 5 than in groups 1,2 and $3(p<0.01$; Fig. 6).

\section{Discussion}

The standard 12-lead ECG is widely used for the assessment of left ventricular hypertrophy. Asymmetric septal hypertrophy in some patients 
with hypertension, especially in patients with borderline hypertension has been reported.9),10) Using 12-lead ECGs, we were able to estimate the existence of left ventricular hypertrophy, but not the site of hypertrophy. In this study we tried to determine the hypertrophic site of left ventricular hypertrophy by body surface mapping using the departure map technique which indicates the area of abnormal potential outside the normal range.

On the departure maps of hypertensive patients, a $+2 \mathrm{SD}$ area was found on the middle anterior chest at $20 \mathrm{msec}$, and moved leftward at 30 and $40 \mathrm{msec}$. At $50 \mathrm{msec}$, the $+2 \mathrm{SD}$ area was located on the left lateral chest, and at $60 \mathrm{msec}$ mainly on the back. The location of the $+2 \mathrm{SD}$ area was similar to the location of maximal potential observed on isopotential maps of a normal subject, and so the location of the $+2 \mathrm{SD}$ area probably reflects the increase of electromotive force of the left ventricle.

Based on the appearance time of the $+2 \mathrm{SD}$ area, we classified patients into 5 groups, groups 1-5. ST was greater in groups 2 and 5, that have a $+2 \mathrm{SD}$ area at $20 \mathrm{msec}$. PWT was greater in groups 4 and 5 , that have a $+2 \mathrm{SD}$ area at $60 \mathrm{msec}$. The activation time of the intraventricular septum (IVS) is $10-15 \mathrm{msec}$, and the activation time of the left ventricular posterior wall (LVPW) is 40-60 msec. ${ }^{11}$ Thus, we postulate that the increased and delayed electrical potential due to hypertrophy of the IVS is represented as a $+2 \mathrm{SD}$ area at an early period of the QRS, especially at $20 \mathrm{msec}$, and the increased and delayed potential due to hypertrophy of the LVPW is represented as a +2SD area at a late period of the QRS, especially at $60 \mathrm{msec}$. In group 3, ST and PWT did not significantly increase. +2SD areas seen at the middle of the QRS, that is, $+2 \mathrm{SD}$ areas at 30,40 and $50 \mathrm{msec}$ were not related to hypertrophy of the IVS or LVPW. These may reflect hypertrophy of the anterior or lateral walls. In this study, we used M-mode echocardiograms, and therefore did not measure the thickness of the anterior or lateral walls. Whether the appearance of +2SD areas at 30, 40 and $50 \mathrm{msec}$ was due to hypertrophy of the anterior or lateral walls or not remains an issue for further investigation.

LVM had a tendency to increase with the number of the group from 1 to 5 , and in groups 4 and 5, the groups with +2SD areas at $60 \mathrm{msec}$, LVM was significantly greater than in groups 1,2 and 3 , the groups without $+2 \mathrm{SD}$ areas at $60 \mathrm{msec}$. The $+2 \mathrm{SD}$ area at $60 \mathrm{msec}$ was located on the left lateral chest or back. These results agree with the conventional VCG findings that the leftward and posterior component of the mid to late period of the QRS loop is increased in moderate to severe $\mathrm{LVH}^{12}{ }^{12}$

$S V_{1}+R V_{5}$ or $V_{6}$ was significantly greater in group 5 than in groups $1,2,3$ and 4. LVM was greatest in group 5, $S V_{1}+R_{5}$ or $V_{6}$ roughly 
indicated the existence of left ventricular hypertrophy. Devereux et al reported that a significant linear correlation was found between $S V_{1}+R V_{5}$ or $V_{6}$ and LVM, and that LVM was significantly greater in the group with increased $\mathrm{SV}_{1}+\mathrm{RV}_{5}$ or $\mathrm{V}_{6}(>3.5 \mathrm{mV})$ than in the group without increased $\mathrm{SV}_{1}+\mathrm{RV}_{5}$ or $\mathrm{V}_{6} \cdot{ }^{6}$

LVM was significantly smaller in groups 1,2 and 3 . The patients were significantly younger in group 1, and known duration of hypertension was significantly shorter in groups 1,2 and 3. Thus, groups 1,2 and 3 might be at earlier phases of LVH. In this study, many of the patients were being treated with antihypertensive therapy. Some authors have reported that left ventricular morphology is modified by antihypertensive therapy. ${ }^{13), 14}$ ) In order to prove that groups 1,2 and 3 are in early phases of $\mathrm{LVH}$, a followup study should be done.

In conclusion, body surface mapping, especially the departure map technique, is a useful method to detect the abnormal electrical potential distribution of patients with left ventricular hypertrophy and to localize the site of hypertrophy.

\section{REFERENGES}

1. Flowers NG, Horan LG, Johnson JC: Anterior infarctional changes occurring during mid and late ventricular activation detectable by surface mapping techniques. Circulation 54: 906,1976

2. Ikeda K, Kubota I, Tonooka I, Tsuiki K, Yasui S: Detection of posterior myocardial infarction by body surface mapping: A comparative study with 12 lead ECG and VCG. J Electrocardiology $18: 361,1985$

3. Tonooka I, Kubota I, Watanabe Y, Tsuiki K, Yasui S: Isointegral analysis of body surface maps for the assessment of location and size of myocardial infarction. Am J Cardiol 52: 1174,1983

4. Watanabe T, Toyama J, Toyoshima H, Oguri H, Ohno M, Ohta T, Okajima M, Naito Y, Yamada K: A practical minicomputer based mapping system for body surface, precordium and epicardium. Comput Biomed Res 14: 341, 1981

5. Sokolow M, Lyon TP: The ventricular complex in left ventricular hypertrophy as obtained by unipolar precordial and limb leads. Am Heart J 37: 161, 1949

6. Devereux RB, Phillips MC, Casale PN, Eisenberg RR, Kligfield P: Geometric determinants of electrocardiographic left ventricular hypertrophy. Circulation 67: 907, 1983

7. Sahn DJ, DeMaria A, Kisslo J, Weyman A: Committee on M-mode Standardization of the American Society of Echocardiography: Recommendations regarding quantification in Mmode echocardiography: results of a survey of echocardiographic measurements. Circulation 58: 1072,1978

8. Devereux RB, Reichek N: Echocardiographic determination of left ventricular mass in man. Anatomic validation of the method. Circulation 55: 613, 1977

9. Cohen A, Hagan AD, Watkins J, Mitas J, Schvartzman M, Mazzoleni A, Cohen IM, Warren SE, Vieweg WV: Clinical correlates in hypertensive patients with left ventricular hypertrophy diagnosed with echocardiography. Am J Cardiol 47: 335, 1981

10. Safar ME, Lehner JP, Vincent MI, Plainfosse MT, Simon ACh: Echocardiographic dimen- 
sions in borderline and sustained hypertension. Am J Cardiol 44: 930, 1979

11. Durrer D, Dam RT, Freud GE, Janse MJ, Meijler FL, Arzbaecher RC: Total excitation of the isolated human heart. Circulation $41: 899,1970$

12. Cookcey JD, Dunn M, Massie E: Clinical Vectorcardiography and Electrocardiography, 2nd Ed, Year Book Medical Publishers, Chicago, London, 1977

13. Devereux RB: Non-invasive evaluation of cardiac anatomy and function in patients with hypertension. Cardiovasc Rev Rep 3: 313, 1982

14. Drayer JIM, Gardin JM, Weber MA: Echocardiographic left ventricular hypertrophy in hypertension. Chest $84: 217,1983$ 